\title{
Assessment of Arthrobacter viscosus as reactive medium for forming permeable reactive biobarrier applied to PAHs remediation
}

\author{
L. Ferreira • M. Cobas • T. Tavares • M. A. Sanromán • \\ M. Pazos
}

Received: 1 March 2013 / Accepted: 15 April 2013 / Published online: 3 May 2013

(C) Springer-Verlag Berlin Heidelberg 2013

\begin{abstract}
Polycyclic aromatic hydrocarbons (PAHs) are significant environmental contaminants as they are present naturally as well as anthropogenically in soil, air and water. In spite of their low solubility, PAHs are spread to the environment, and they are present in surface water, industrial effluent or groundwater. Amongst all remediation technologies for treating groundwater contaminated with PAHs, the use of a permeable reactive biobarrier (PRBB) appears to be the most cost-effective, energy efficient, and environmentally sound approach. In this technology, the microorganisms are used as reactive medium to degrade or stabilize the contaminants. The main limits of this approach are that the microorganisms or consortium used for forming the PRBB should show adequate characteristics. They must be retained in the barrier-forming biofilm, and they should also have degradative ability for the target pollutants. The aim of the present work is to evaluate the viability of Arthrobacter viscosus as bioreactive medium for forming PRBB. Initially, the ability of $A$. viscosus to remove PAHs, benzo[a]anthracene $100 \mu \mathrm{M}$ and phenanthrene $100 \mu \mathrm{M}$ was evaluated operating in a batch bench-scale bioreactor. In both cases, total benzo[a]anthracene and phenanthrene removals were obtained after 7 and 3 days, respectively.
\end{abstract}

Responsible editor: Philippe Garrigues

L. Ferreira $\cdot$ M. Cobas $\cdot$ M. A. Sanromán $\cdot$ M. Pazos $(\bowtie)$

Department of Chemical Engineering, University of Vigo,

Vigo 36310, Spain

e-mail: mcurras@uvigo.es

T. Tavares

Department of Biological Engineering, University of Minho, Braga 4710-057, Portugal
Furthermore, the viability of the microorganisms was evaluated in the presence of chromium in a continuous mode. As a final point, the adhesion of $A$. viscosus to sepiolite forming a bioreactive material to build PRBB was demonstrated. In view of the attained results, it can be concluded that $A$. viscosus could be a suitable microorganism to form a bioreactive medium for PAHs remediation.

Keywords A. viscosus $\cdot$ Benzo[a]anthracene $\cdot$ Bioreactive medium $\cdot$ PAHs $\cdot$ Phenanthrene $\cdot$ PRBB

\section{Introduction}

Polycyclic aromatic hydrocarbons (PAHs) are significant environmental contaminants as they are present naturally as well as anthropogenically. Their presence in surface water and groundwater is due to the atmospheric sedimentation, rainwater, industrial effluent ( $\mathrm{He}$ and Balasubramanian 2010) and soil leaching (Manoli and Samara 1999). PAHs degradation is interesting because of their biological and mutagenic effects, toxicity and elevated carcinogenic grade (Haritash and Kaushik 2009). Nowadays, the water decontamination process is limited by an excessive usage of chemicals, expensive plant requirements and high operational costs (Quintelas et al. 2010). Amongst all remediation technologies for treating contaminated groundwater, the use of permeable reactive barriers (PRBs) appears to be the most cost-effective, energy efficient and environmentally sound approach (Thiruvenkatachari et al. 2008).

In this approach, groundwater flows through a highly permeable reactive zone of the system, under the effect of 
the natural hydraulic gradient. Therefore, the dissolved contaminants in the plume can be captured by sorption in the barrier filling material, removed by chemical reactions or biodegraded by the microorganisms attached to the barrier. PRBs are considered passive systems, that is to say that only limited maintenance is necessary and no ongoing energy input is required (Saponaro et al. 2009).

This technology can increase its efficiency by the coupling of another remediation technique such as bioremediation. The main principle of bioremediation technology is to remove pollutants from the natural environment and/or transform the pollutants to less dangerous products using microbiological activity. Several researches have determined the biodegradative capacity of PAHs of both bacteria and fungi in contaminated land and waters (Bamforth and Singleton 2005). It involves the breakdown of organic compounds through mineralization into inorganic minerals, $\mathrm{H}_{2} \mathrm{O}$, $\mathrm{CO}_{2}$ (aerobic) or $\mathrm{CH}_{4}$ (anaerobic). Thus, PRBs can be coupled with bioremediation forming the named permeable reactive biobarrier technology (PRBB). In this technology, the microorganisms retained in a porous support are used as reactive medium to degrade or stabilize the contaminants (Tiehm et al. 2008). The main limits of this approach are that the microorganisms or consortium used for forming the PRBB should show adequate characteristics such as the barrier-forming biofilm with degradative ability for the target pollutants.

Arthrobacter species are of particular interest because of their high potential for bioremediation. These bacteria can detoxify metal wastewater by reduction or accumulation inside the cells and/or adsorption on their surface (Blázquez et al. 2009). Furthermore, several strains of this genus have been reported as degrading of aromatic compounds which include 4-fluorophenol, 4-chlorobenzoate, phenol, $p$-hydroxybenzoic acid and mono- and dichlorinated biphenyls (Ferreira et al. 2008; Furukawa and Chakrabarty 1982; Karigar et al. 2006; Zaitsev et al. 1991). Amongst these strains, the species Arthrobacter viscosus shows high potential as bioreactive medium for the development of PRBB. This microorganism is well known for the removal of several organic compounds such as diethylketone, phenol, chlorophenol, $o$-cresol (Costa et al. 2012; Quintelas et al. 2010) as well as metals (Lameiras et al. 2008; Pazos et al. 2010). On the other hand, A. viscosus is a non-pathogenic soil bacterium that produces a high amount of viscous extracellular polysaccharides (López et al. 2003). This characteristic permits prediction of good adhesion to different support structures favouring its use as bioreactive medium. Nevertheless, to the best of our knowledge, there is no report in the literature on the use of PAHs as carbon source and energy by $A$. viscosus.

Based on these previous results, the aim of the present work is to assess the viability of $A$. viscosus as bioreactive medium for forming PRBB to PAHs removal. Accordingly, the ability of $A$. viscosus to PAHs removal was assayed in a bench-scale bioreactor, in batch and continuous mode. Finally, the growth of $A$. viscosus over a low-cost support was evaluated.

\section{Materials and methods}

Microorganism and growth

A. viscosus (CECT 908) was obtained from the Spanish Type Culture Collection of the University of Valencia (Spain). The bacterium was maintained at $4{ }^{\circ} \mathrm{C}$ on solid agar petri plates that contained per litre: $10 \mathrm{~g}$ glucose, $5 \mathrm{~g}$ peptone, $3 \mathrm{~g}$ malt extract, $3 \mathrm{~g}$ yeast extract and $15 \mathrm{~g}$ agar

The bioreactor inoculum was obtained by submerged bacterium cultures prepared in 250-mL Erlenmeyer flasks with $50 \mathrm{~mL}$ of a culture medium $(\mathrm{CM})$. The $\mathrm{CM}$ contained per litre: $10 \mathrm{~g}$ glucose, $5 \mathrm{~g}$ peptone, $3 \mathrm{~g}$ malt extract and $3 \mathrm{~g}$ yeast extract. The medium $\mathrm{pH}$ was initially adjusted to 7 with $\mathrm{HCl}$ $0.5 \mathrm{M}$. The $\mathrm{CM}$ was autoclaved at $121{ }^{\circ} \mathrm{C}$ for $20 \mathrm{~min}$. The flasks were inoculated, plugged with cellulose stoppers for passive aeration and incubated in an orbital shaker at $28{ }^{\circ} \mathrm{C}$ and $180 \mathrm{rpm}$.

\section{Support}

Naturally occurring sepiolite, provided by Tolsa S.A., was assayed as a low-cost support for the retention of A. viscosus bacterium. This support has high porosity and allows the exchange of nutrients and/or the flow of the medium through it. The clay mineral has a particle size between 0.5 and $0.125 \mathrm{~mm}$, and its composition is detailed in Table 1 .

\section{Polluted media}

The polluted medium (PM) was composed of malt extract $3 \mathrm{~g} / \mathrm{L}$, yeast extract $3 \mathrm{~g} / \mathrm{L}$, Tween $801 \%$, acetone $2 \%$ and $100 \mu \mathrm{M}$ PAHs (Moscoso et al. 2012a, b; Rosales et al. 2012).
Table 1 Sepiolite mineralogical analysis by $\mathrm{X}$-ray fluorescence (FRX)

\begin{tabular}{ll}
\hline Compound & Percentage \\
\hline $\mathrm{SiO}_{2}$ & 63.45 \\
$\mathrm{MgO}$ & 22 \\
$\mathrm{Al} \mathrm{O}_{3}$ & 6.81 \\
$\mathrm{CaO}$ & 3.48 \\
$\mathrm{~K}_{2} \mathrm{O}$ & 1.9 \\
$\mathrm{Fe}_{2} \mathrm{O}_{3}$ & 1.63 \\
$\mathrm{Na}_{2} \mathrm{O}$ & 0.3 \\
$\mathrm{TiO}_{2}$ & 0.246 \\
$\mathrm{SO}_{3}$ & 0.11 \\
$\mathrm{MnO}$ & 0.04 \\
$\mathrm{P}_{2} \mathrm{O}_{5}$ & 0.04 \\
\hline
\end{tabular}


In the experiment where the presence of metals was evaluated, this medium also contained $100 \mathrm{mg} / \mathrm{L}$ of $\mathrm{Cr}(\mathrm{VI})$. The $\mathrm{pH}$ of the PM was initially adjusted to 7 with $\mathrm{HCl} 0.5 \mathrm{M}$, and after that, the medium was autoclaved at $121{ }^{\circ} \mathrm{C}$ for $20 \mathrm{~min}$. Pollutant concentration was analysed after the sterilization process to assure that the pollutant was not destroy/volatilized during this process.

Bench-scale bioreactor experimental set-up

A Biostat B airlift bioreactor (B. Braun, Germany) with a working volume of $1.5 \mathrm{~L}$ was employed (Fig. 1). The bioreactor can operate in batch and continuous mode. The temperature was maintained at $28{ }^{\circ} \mathrm{C}$ by circulation of thermostatted water. The bioreactor was inoculated with actively growing cells from flask cultures $(6 \% v / v)$. Humidified air was continuously supplied at flow rate of $0.33 \mathrm{vvm}$, and samples were regularly taken during the experimental period. The continuous experiments were developed with similar operational conditions than the bench-scale bioreactor connected with peristaltic pumps.

Immobilization onto sepiolite experimental set-up

Immobilization of $A$. viscosus onto sepiolite was carried out via submerged aerobic culture prepared in a 250-mL Erlenmeyer flask with $50 \mathrm{~mL}$ of PM and $9.5 \mathrm{~g}$ of sepiolite clay. The flask containing the sepiolite and PM was sterilized at $121{ }^{\circ} \mathrm{C}$ for $20 \mathrm{~min}$. After that, it was inoculated and incubated for 7 days at $28{ }^{\circ} \mathrm{C}$ and $180 \mathrm{rpm}$ with a passive aeration permitted by cellulose stoppers.

Sample treatment and analysis

PAHs analysis

PAHs concentration in the supernatant was determined by HPLC (Agilent 1100) equipped with an XDB-C8 reversephase column $(150 \times 4.6 \mathrm{~mm}$ i.d., $5 \mu \mathrm{m})$. Prior to injection, the samples were centrifuged $(10,000 \mathrm{rpm}, 5 \mathrm{~min})$ and filtered through a $0.45-\mu \mathrm{m}$ Teflon filter. The injection volume was set at $5 \mu \mathrm{L}$, and the isocratic eluent (60:40 acetonitrile/water) was pumped at a rate of $1 \mathrm{~mL} / \mathrm{min}$ for $10 \mathrm{~min}$. Detection was performed with a diode array detector from 200 to $400 \mathrm{~nm}$, and the column temperature was maintained at $20{ }^{\circ} \mathrm{C}$ (Alcántara et al. 2009).

Extracellular polysaccharide measure

The samples were centrifuged $\left(8,000 \mathrm{rpm}, 4{ }^{\circ} \mathrm{C}\right.$ and $\left.30 \mathrm{~min}\right)$, and the polysaccharides were estimated in the supernatant using ethanol precipitation $(2: 1, v / v)$ in the presence of $1 \%$ $\mathrm{KCl}$. After $24 \mathrm{~h}$ at $4{ }^{\circ} \mathrm{C}$, the precipitated biopolymer was separated by centrifugation $\left(8,000 \mathrm{rpm}\right.$ for $30 \mathrm{~min}$ at $\left.4{ }^{\circ} \mathrm{C}\right)$ and quantified by dry-weight determination (López et al. 2003).

$\mathrm{pH}$

The $\mathrm{pH}$ in liquid samples was measured directly with an IQ Scientific Instruments $\mathrm{pH}$ metre (model Stainless Steel ISFET pH Probes).

Biomass determination

Cell growth was determined by spectrophotometer Helios Beta (Thermo Electron Corporation) at $620 \mathrm{~nm}$. Previously, the samples were centrifuged $(10,000 \mathrm{rpm}, 5 \mathrm{~min})$, the pellet was resuspended in distilled water, and the obtained values were converted to gram cell dry wt per litre using a calibration curve (López et al. 2003).

Scanning electron microscopy analyses

A series of environmental scanning electron microscopy (ESEM) images was taken to provide a visual characterization of the A. viscosus grown over sepiolite. Images were collected on a FEI-Quanta 200 environmental scanning electron microscope using an accelerating voltage of $15 \mathrm{kV}$ (Electron Microscopy Service, C.A.C.T.I., University of Vigo).

\section{Results and discussion}

The reactivity of the materials used to form a barrier is crucial in the design of PRBB. Therefore, the objective in this work was to evaluate the viability of $A$. viscosus as bioreactive medium for PAHs removal. For this purpose, several experimental tests were designed in order to determine the two main factors: degradation and adhesion ability. Initially, the ability of A. viscosus to PAHs removal was assayed in a bench-scale bioreactor in batch mode. Two different PAHs were tested, and the influence of chromium in the aqueous environment was also evaluated. After that, the removal capacity of the microorganism along the time was analysed in a continuous assay. Finally, the bacterial growth over a low-cost support, the sepiolite clay, was studied.

PAHs removal by A. viscosus: batch assays

The capability of the bacterium $A$. viscosus to degrade PAHs was evaluated using a bench-scale bioreactor in batch mode. Two different PAHs, phenanthrene (PHE), a three-ring aromatic compound, and benzo[a]anthracene (BAA), a four-ring aromatic compound, were selected. These substances are widely used as indicators of PAHs pollution and have been appointed as EPA priority pollutants (Alcántara et al. 2009; 
Fig. 1 Bench-scale bioreactor Batch process 1 , heating water in; 2 , heating water out; 3 , air inlet, 4, sampling, 5 , air outlet and 6, microorganism and PM. Continuous process 7 , PM bottle outlet; 8 , PM bottle inlet; 9 , peristaltic pump and 10 , switch for continuous process

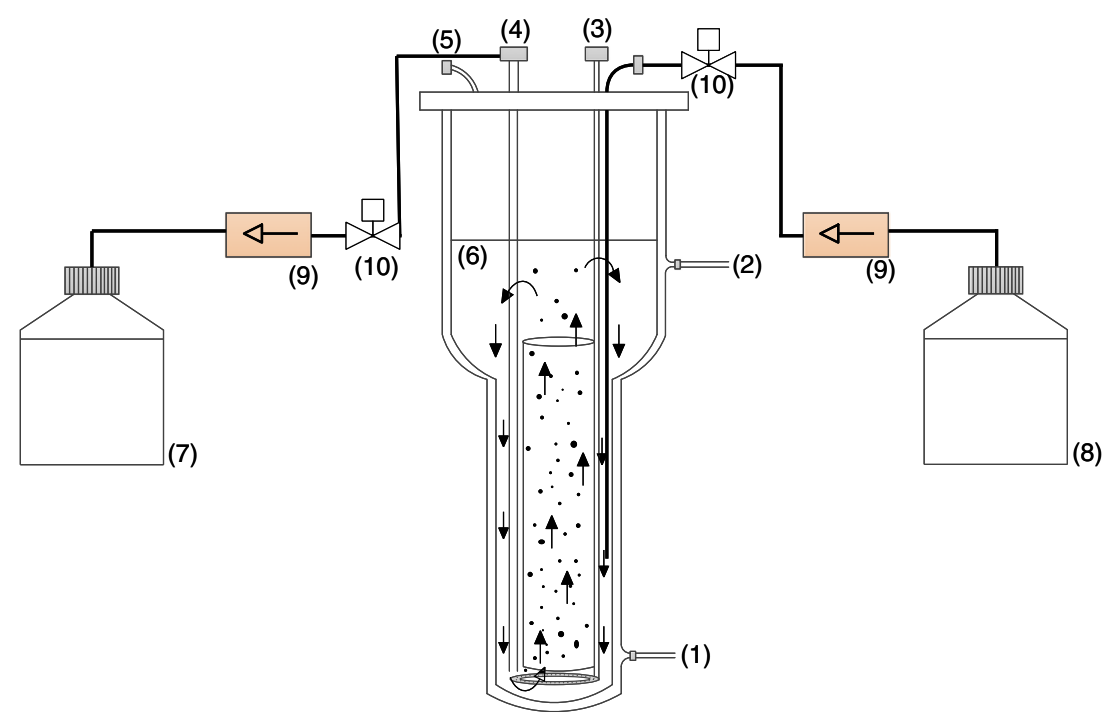

Sack et al. 1997). Initially, batch assays using PHE as pollutant were performed in the bioreactor (Fig. 2). In the first batch, the fast removal of PHE from aqueous solution during the first day is attributed to the adsorption of aromatic compound to the bacterium biomass. According to Raghukumar et al. (2006), once the PAHs are adsorbed by the biomass, they are subsequently metabolized by the microorganisms as carbon source. Samanta et al. (1999) determined that $30 \%$ of removal of PHE was achieved by Arthrobacter sulphurous after $18 \mathrm{~h}$. In the following batches, the PHE removal rates were decreased, around $40 \%$ lower than obtained in the first batch. This fact could be due to biomass saturation as a result of the adsorption experimented in the first batch. The $\mathrm{pH}$ in the reactor was monitored during the treatment, and alkaline environment, $\mathrm{pH}=8-9$, was determined in all batches. These results are in accordance with those reported by Peng et al. (2012). They determined that keeping the water body under a slightly

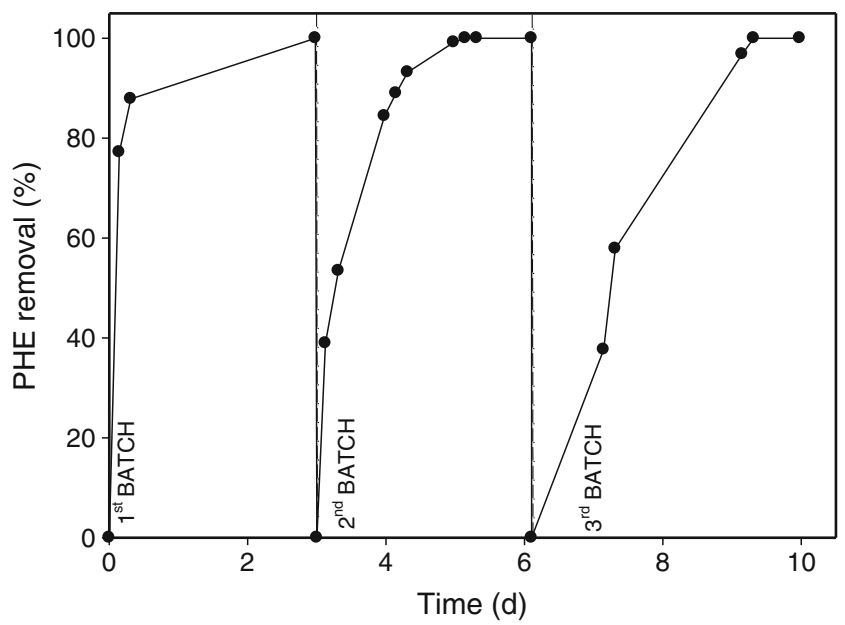

Fig. 2 PHE removal in bench-scale bioreactor by A. viscosus during three successive batches alkaline condition is propitious for PAHs degradation by Arthrobacter species.

In a second stage, the removal of the four-ring aromatic compound, BAA, was evaluated (Fig. 3). The rapid adsorption of the pollutant in the first hours of treatment was also observed in this experiment. The removal obtained after the first day was higher than $70 \%$. Similarly to the previous experiment, the environment was propitious to PAHs removal because alkaline conditions, $\mathrm{pH}=8-9$, were developed in the reactor during the experiments. As it was expected, according to its greater structure, the observed removal rate was lower than the previous one. Total BAA removal was obtained after 7 days. This fact is a promising result because less is known about the bacteria capable of utilizing PAHs containing four or more rings as a carbon and energy source, and it has been reported that only fungi can degrade these types of PAHs (Peng et al. 2008; Rosales et al. 2012).

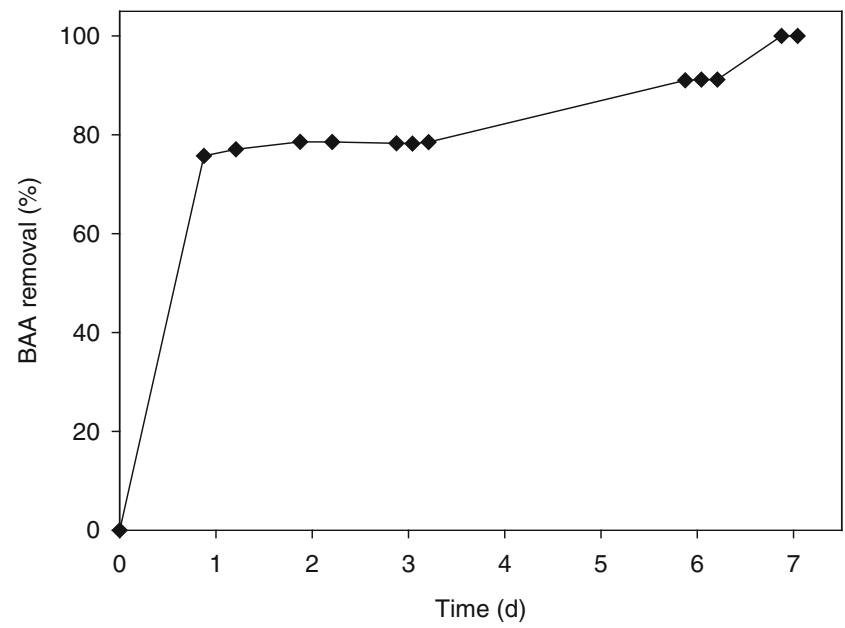

Fig. 3 BAA removal in bench-scale bioreactor by A. viscosus 


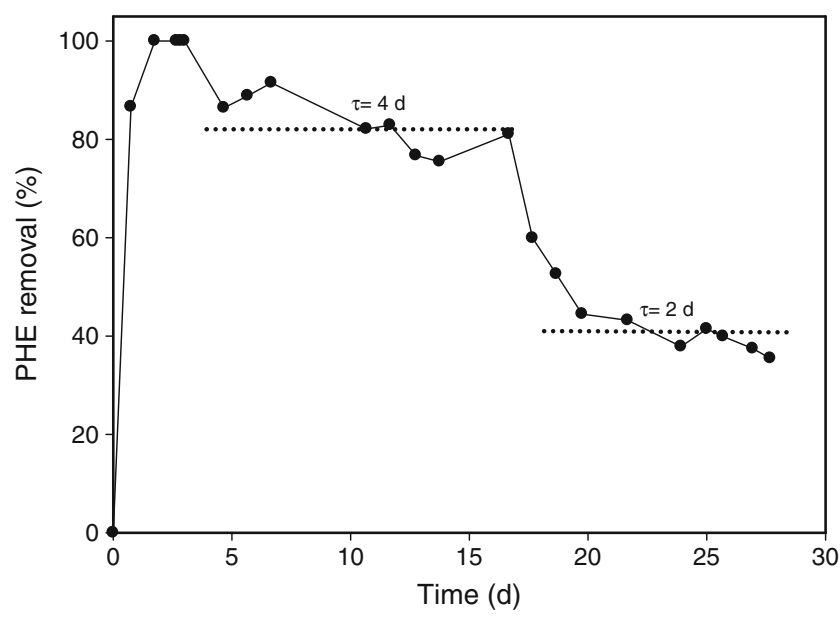

Fig. 4 PHE continuous removal in bench-scale bioreactor by $A$. viscosus

PHE removal by $A$. viscosus: continuous assay

To evaluate the loss of removal property of the microorganism along the time, a continuous experiment was developed in the bench-scale bioreactor. Two different residence times, 4 and 2 days, were tested (Fig. 4). Working at the residence time of 4 days, the reactor reached a stable performance with an average removal degree of $80 \%$. This removal was lower than what was obtained in batch assays, where after 3 days, total removal was obtained. This fact could be attributed to the decrease of biomass around $30 \%$ inside the reactor. Similar behaviour was detected when the PM flow was increased. Thus, at the residence time of 2 days, the cell wash-out increased, meaning a low removal rate of around $40 \%$.

\section{PHE and $\mathrm{Cr}(\mathrm{VI})$ removal by A. viscosus}

The existence of metals in the water bodies is frequently found along with organic pollutants in the environment. Their presence

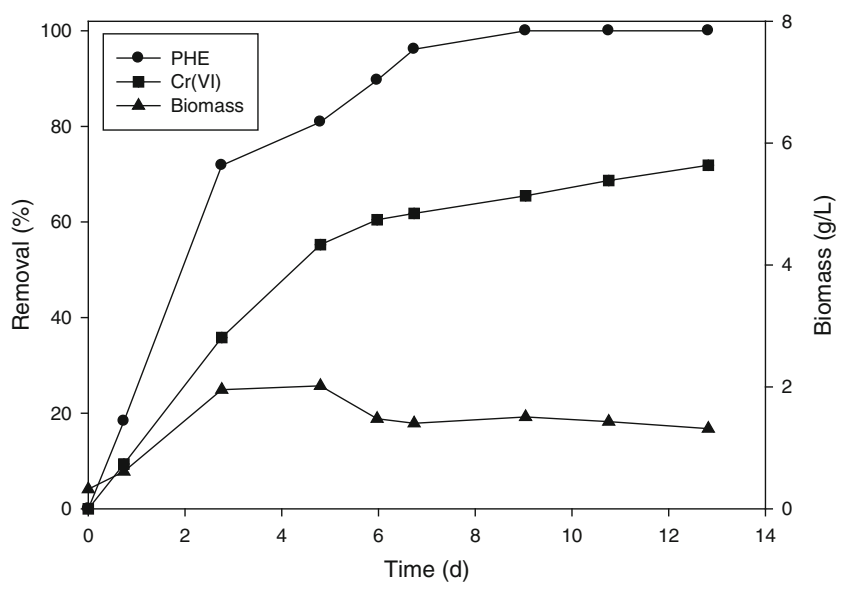

Fig. 5 Biomass concentration, $\mathrm{PHE}$ and $\mathrm{Cr}(\mathrm{VI})$ removal profiles in bench-scale bioreactor can have significantly detrimental effects on the flora, fauna and human health (Akpor and Muchie 2010; Nadal et al. 2011). The common metals that have been identified in polluted water include arsenic, copper, cadmium, lead, chromium, nickel, mercury and zinc (Akpor and Muchie 2010). Therefore, the influence of PAHs remediation by $A$. viscosus in the presence of soluble metal, such as $\mathrm{Cr}(\mathrm{VI})$, was evaluated. For this purpose, a new experiment in batch mode was designed in which PHE and $\mathrm{Cr}(\mathrm{VI})$ were in the medium. In Fig. 5, the removal degrees during the time of both pollutants in the bench-scale bioreactor are shown. Following the behaviour observed in the previous studies, the PHE removal rate was higher during the first days, reaching $80 \%$ of removal after 2 days. This fact is also related with the increase of biomass in the system of around $2 \mathrm{~g} / \mathrm{L}$. In this experiment, the presence of $\mathrm{Cr}(\mathrm{VI})$ reduced the PHE removal rate. The PHE total removal was reached after 8 days. It is postulated that the microorganisms need more time to adapt their metabolic activity to both pollutants. Nevertheless, around $72 \%$ of $\mathrm{Cr}(\mathrm{VI})$ was also eliminated from the medium. The ability of $\mathrm{Cr}(\mathrm{VI})$ anions to overcome the permeable membrane of the bacterium can be attributed to the chemical similarity between $\mathrm{CrO}_{4}{ }^{2-}$ and $\mathrm{SO}_{4}{ }^{2-}$ ions (Mabbett and Macaskie 2001). Once the $\mathrm{Cr}(\mathrm{VI})$ penetrates into the cell, it can be reduced to $\mathrm{Cr}$ (III) that is known to be the main detoxification mechanism of $A$. viscosus due to its reductase activity (Çetin et al. 2008; Srinath et al. 2002). After treatment, total chromium was measured in the liquid medium in order to determine the chromium absorption by the biomass. Around $42 \%$ of initial $\mathrm{Cr}(\mathrm{VI})$ was liberated to the medium as $\mathrm{Cr}(\mathrm{III})$, meaning that the biomass absorption of chromium was around $30 \%$. These results are promising because in our knowledge, the removal of $\mathrm{Cr}(\mathrm{VI})$ and PHE via $A$. viscosus bacterium was not reported previously.

\section{A. viscosus immobilization onto sepiolite}

Once the capacity of pollutant removal using the $A$. viscosus bacterium was demonstrated, the following issue was to evaluate microorganism adhesion onto an adequate support. General requirements such as porous structure, low cost, hydraulic conductivity, eco-friendliness and mechanical stability should be taken into consideration for the selection of appropriate support to PRBBs. Among the different available supports, the clay mineral sepiolite seems to be an appropriate candidate. Sepiolite exhibits microfibrous morphology with a high specific surface area (around $340 \mathrm{~m}^{2} / \mathrm{g}$ ) and a large micropore volume (around $0.44 \mathrm{~cm}^{3} / \mathrm{g}$ ) due to the existence of intracrystalline cavities ("tunnels") (Rytwo et al. 1998). Furthermore, this clay has powerful sorbent properties and ability to adsorb inorganic and organic species too (Kocaoba 2009; Quintelas et al. 2011).

On the other hand, $A$. viscosus belongs to the soil bacterium species that produces a high amount of viscous extracellular polysaccharides (López et al. 2003) which favour bacterium 
Fig. 6 ESEM images of $A$. viscosus supported on sepiolite in presence of $100 \mu \mathrm{M}$ PHE and BAA and $100 \mathrm{mg} / \mathrm{L} \mathrm{Cr}$ (VI). a initial, $\mathbf{b}$ after 7 days and $\mathbf{c}$ surface detail after 7 days
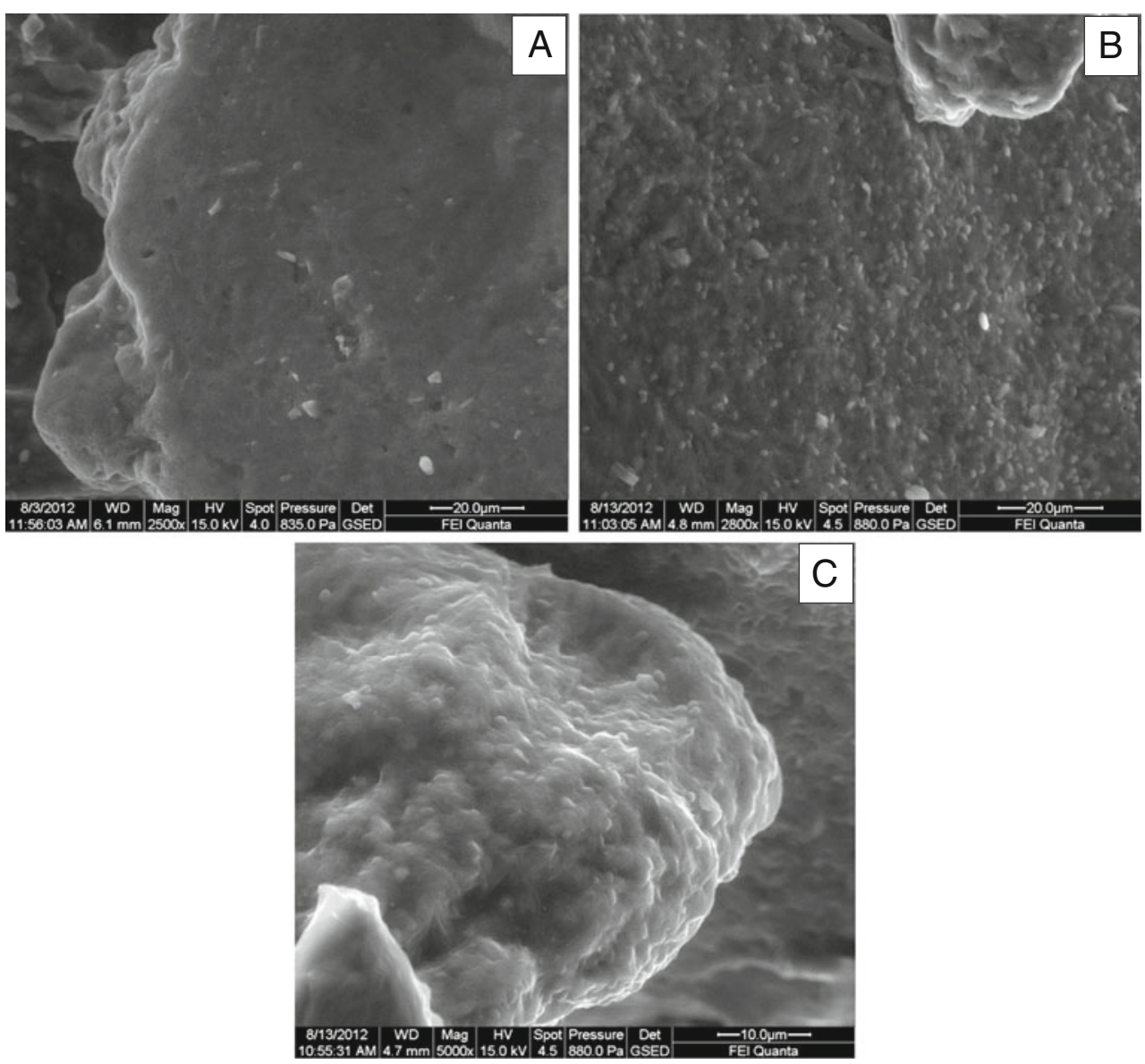

adhesion to different supports. This fact, along with sepiolite characteristics, make their combination an adequate system to form bioreactive material for PRBB. It is expected that sepiolite porous structure will favour bacterium adhesion and will allow the retention of pollutant, increasing the contact time between the pollutant and the bacterium.

The adhesion of the microorganisms onto sepiolite was studied by ESEM microscopy, and it was accomplished in the presence of $100 \mu \mathrm{M}$ PHE and BAA and $100 \mathrm{mg} / \mathrm{L} \mathrm{Cr}$ (VI). In Fig. 6, the ESEM images of sepiolite initially (Fig. 6a) and after 7 days (Fig. 6b and c) demonstrated that the bacterium colonized the sepiolite surface. In these images can be clearly appreciated high biomass density after 7 days. This experiment was performed in the presence of PHE, BAA and $\mathrm{Cr}$ (VI) in order to analyse their influence on polysaccharide secretion. After 7 days, the extracellular polysaccharides were determined in the supernatant, and a moderate level (1.89 $\mathrm{g} / \mathrm{g}$ biomass) of polysaccharides was detected. These results are in agreement to that reported by López et al. (2003) who obtained similar levels of polysaccharide production by $A$. viscosus. Accordingly, it can be concluded that the presence of pollutants did not interfere in the secretion of polysaccharides. These results clearly show that sepiolite is a suitable support for $A$. viscosus to form bioreactive material for the development of PRBB.

\section{Conclusions}

In this work, the $A$. viscosus soil bacterium was assessed to form PRBB applied to PAHs removal. In a first step, A. viscosus bacterium was evaluated to remove high and low molecular weight PAHs operating in a batch benchscale bioreactor. For both cases, total BAA and PHE removals were obtained after 7 and 3 days, respectively. Furthermore, the bacterium's ability for BAA and PHE removal was positively evaluated during the time period in the presence of $\mathrm{Cr}(\mathrm{VI})$. As a final point, the adhesion of $A$. viscosus to sepiolite forming a bioreactive material to build PRBB was demonstrated. Accordingly, in the assayed conditions, the developed bioreactive material can be an appropriate candidate to be employed in PRBB applied to treat aqueous samples polluted with PAHs. Further studies are necessary, using real samples to assess the efficiency of the technology.

Acknowledgments This work has been supported by the Spanish Ministry of Economy and Competitiveness and FEDER Funds (Project CTM 2011-25389). Marta Pazos received financial support under the Ramón y Cajal programme and Marta Cobas under the final project master grant "Campus do Mar Knowledge in depth". 


\section{References}

Akpor OB, Muchie M (2010) Remediation of heavy metals in drinking water and wastewater treatment systems: processes and applications. Int J Phys Sci 5:1807-17

Alcántara MT, Gómez J, Pazos M, Sanromán MA (2009) PAHs soil decontamination in two steps: desorption and electrochemical treatment. J Hazard Mater 166:462-8

Bamforth SM, Singleton I (2005) Bioremediation of polycyclic aromatic hydrocarbons: current knowledge and future directions. J Chem Technol Biotechnol 80:723-36

Blázquez G, Hernáinz F, Calero M, Martín-Lara MA, Tenorio G (2009) The effect of $\mathrm{pH}$ on the biosorption of $\mathrm{Cr}$ (III) and $\mathrm{Cr}$ (VI) with olive stone. Chem Eng J 148:473-9

Çetin D, Dönmez S, Dönmez G (2008) The treatment of textile wastewater including chromium(VI) and reactive dye by sulfatereducing bacterial enrichment. J Environ Manage 88:76-82

Costa F, Quintelas C, Tavares T (2012) Kinetics of biodegradation of diethylketone by Arthrobacter viscosus. Biodegradation 23:8192

Ferreira MIM, Marchesi JR, Janssen DB (2008) Degradation of 4fluorophenol by Arthrobacter sp. strain IF1. Appl Microbiol Biotechnol 78:709-17

Furukawa K, Chakrabarty AM (1982) Involvement of plasmids in total degradation of chlorinated biphenyls. Appl Environ Microbiol 44:619-26

Haritash AK, Kaushik CP (2009) Biodegradation aspects of polycyclic aromatic hydrocarbons (PAHs): a review. J Hazard Mater 169:1-15

He J, Balasubramanian R (2010) Semi-volatile organic compounds (SVOCs) in ambient air and rainwater in a tropical environment: concentrations and temporal and seasonal trends. Chemosphere $78: 742-51$

Karigar C, Mahesh A, Nagenahalli M, Yun DJ (2006) Phenol degradation by immobilized cells of Arthrobacter citreus. Biodegradation 17:47-55

Kocaoba S (2009) Adsorption of Cd(II), Cr(III) and Mn(II) on natural sepiolite. Desalination 244:24-30

Lameiras S, Quintelas C, Tavares T (2008) Biosorption of Cr (VI) using a bacterial biofilm supported on granular activated carbon and on zeolite. Bioresour Technol 99:801-6

López E, Ramos I, Sanromán MA (2003) Extracellular polysaccharides production by Arthrobacter viscosus. J Food Eng 60:463-7

Mabbett AN, Macaskie LE (2001) A novel isolate of Desulfovibrio sp. with enhanced ability to reduce $\mathrm{Cr}(\mathrm{VI})$. Biotechnol Lett 23:683-7

Manoli E, Samara C (1999) Polycyclic aromatic hydrocarbons in natural waters: sources, occurrence and analysis. TrAC- Trends Anal Chem 18:417-28

Moscoso F, Deive FJ, Longo MA, Sanromán MA (2012a) Technoeconomic assessment of phenanthrene degradation by Pseudomonas stutzeri CECT 930 in a batch bioreactor. Bioresour Technol 104:81-9

Moscoso F, Teijiz I, Deive FJ, Sanromán MA (2012b) Efficient PAHs biodegradation by a bacterial consortium at flask and bioreactor scale. Bioresour Technol 119:270-6

Nadal M, Schuhmacher M, Domingo JL (2011) Long-term environmental monitoring of persistent organic pollutants and metals in a chemical/petrochemical area: human health risks. Environ Pollut 159:1769-77

Pazos M, Branco M, Neves IC, Sanromán MA, Tavares T (2010) Removal of Cr(VI) from aqueous solutions by a bacterial biofilm supported on zeolite: optimisation of the operational conditions and scale-up of the bioreactor. Chem Eng Technol 33:2008-14

Peng H, Yin H, Deng J, Ye JS, Chen SN, He BY, Zhang N (2012) Biodegradation of benzo[a]pyrene by Arthrobacter oxydans B4. Pedosphere 22:554-61

Peng RH, Xiong AS, Xue Y, Fu XY, Gao F, Zhao W, Tian YS, Yao QH (2008) Microbial biodegradation of polyaromatic hydrocarbons. FEMS Microbiol Rev 32:927-55

Quintelas C, Figueiredo H, Tavares T (2011) The effect of clay treatment on remediation of diethylketone contaminated wastewater: uptake, equilibrium and kinetic studies. J Hazard Mater 186:1241-8

Quintelas C, Silva B, Figueiredo H, Tavares T (2010) Removal of organic compounds by a biofilm supported on GAC: modelling of batch and column data. Biodegradation 21:379-92

Raghukumar C, Shailaja MS, Parameswaran PS, Singh SK (2006) Removal of polycyclic aromatic hydrocarbons from aqueous media by the marine fungus NIOCC \# 312: involvement of lignindegrading enzymes and exopolysaccharides. Indian J Med Sci 35:373-9

Rosales E, Pérez-Paz A, Vázquez X, Pazos M, Sanromán MA (2012) Isolation of novel benzo[a]anthracene-degrading microorganisms and continuous bioremediation in an expanded-bed bioreactor. Bioprocess Biosyst Eng 35:851-5

Rytwo G, Nir S, Margulies L, Casal B, Merino J, Ruiz-Hitzky E, Serratosa JM (1998) Adsorption of monovalent organic cations on sepiolite: experimental results and model calculations. Clays Clay Miner 46:340-8

Sack U, Heinze TM, Deck J, Cerniglia CE, Martens R, Zadrazil F, Fritsche W (1997) Comparison of phenanthrene and pyrene degradation by different wood-decaying fungi. Appl Environ Microbiol 63:3919-25

Samanta SK, Chakraborti AK, Jain RK (1999) Degradation of phenanthrene by different bacteria: evidence for novel transformation sequences involving the formation of 1-naphthol. Appl Microbiol Biotechnol 53:98-107

Saponaro S, Negri M, Sezenna E, Bonomo L, Sorlini C (2009) Groundwater remediation by an in situ biobarrier: a bench scale feasibility test for methyl tert-butyl ether and other gasoline compounds. J Hazard Mater 167:545-52

Srinath T, Verma T, Ramteke PW, Garg SK (2002) Chromium (VI) biosorption and bioaccumulation by chromate resistant bacteria. Chemosphere 48:427-35

Thiruvenkatachari R, Vigneswaran S, Naidu R (2008) Permeable reactive barrier for groundwater remediation. J Ind Eng Chem 14:145-56

Tiehm A, Müller A, Alt S, Jacob H, Schad H, Weingran C (2008) Development of a groundwater biobarrier for the removal of polycyclic aromatic hydrocarbons, BTEX, and heterocyclic hydrocarbons. Water Sci Technol 58:1349-55

Zaitsev GM, Tsoi TV, Grishenkov VG, Plotnikova EG, Boronin AM (1991) Genetic control of degradation of chlorinated benzoic acids in Arthrobacter globiformis, Corynebacterium sepedonicum and Pseudomonas cepacia strains. FEMS Microbiol Lett 81:171-6 